\title{
Sustainable Education: Legal Regulation and Problems of Practical Implementation in the Context of Specific Territorial Development
}

\author{
Ayzam Akhmedov $^{1}$, Natalia Gromova ${ }^{2,}$, Elena Pashchuk ${ }^{2}$ \\ ${ }^{1}$ Namangan Engineering- Technological Institute, Namangan, Uzbekistan \\ ${ }^{2}$ Ural State University of Economics, Ekaterinburg, Russia \\ *Corresponding author. Email: n.s.gromova@usue.ru
}

\begin{abstract}
The article deals with the peculiarities of sustainable education strategy implementation in Russia. The authors analyze legal regulation of educational relations taking into account global goals of the world community in general and of each state in particular. Moreover, they identify the problems faced by the participants of educational relations within the framework of distance education principles implementation and lifelong learning concept. Applying survey data analysis, the most serious problems in the process of transition to a new type of educational relations are established. We also analyze the risks of educational strategies in modern Russia, taking into account the specific problems of individual territorial units. The authors offer possible ways of mitigating risk strategies and minimizing existing problem areas. They come to the conclusion speaking about possible prospects for the development of educational relations within the implementation of sustainable education strategy.
\end{abstract}

Keywords: sustainable development, sustainable education, distance education, continuing education, risks of educational strategies.

\section{INTRODUCTION}

Every modern state strives for effective development. However, in recent decades, the question how to combine efficiency and stability within the framework of the public relations transformation has increasingly arisen. Scientific discussions allowed articulating problems in the sustainable state development field which led the world community to form a socio-legal strategy that includes a plan to achieve a sustainable future for society through a transformation combination in the economic, social and environmental spheres. The main new policy principles were embodied in the UN General Assembly final document entitled "The Agenda for Sustainable Development for the period up to 2030". This document made it possible to identify 17 global goals facing the world community as a whole and each state in particular. However, it is impossible not to notice that the humanity liberation from poverty and the planet recovery is not going as fast as predicted. In this regard, it is relevant to analyze the implementing tasks process specifics set and identify the problems faced by specific territorial units.
The goal aimed at the educational relations transformation is particular priority, because the integrative effect functional significance in this area cannot be overestimated. High-quality education that meets public needs and state demands makes it possible to make significant progress in stabilizing relations not only within the country, but also provides a positive macroclimate in international relations. The education problem development has not lost its relevance for many years: during the UN World Summit on Environment and Development in Rio de Janeiro in 1992, the leaders of countries and governments recognized that "education is a decisive factor of change." The provision on the need to improve the educational process was also consolidated in September 2002 at the Johannesburg Summit, at which the thesis was put forward on the education consideration in the field of sustainable development as one of the main world community priorities. In 2005, the UN Economic Commission for Europe strategy about education for sustainable development was adopted in Vilnius. Researchers even compare the significance of these facts with the Universal Declaration of Human Rights adoption significance in 1948, which changed the idea of 
the basic rights definition of every person [1]. UN declared the period from 2005 to 2014 the decade of education for sustainable development.

Nowadays, the education process for the younger generation is the foundation for solving important social problems. The sustainable education innovative nature will ensure the implementation of other global goals facing the world community. Consequently, without obtaining new knowledge and skills that accompany a person throughout his life, it is not possible to achieve positive results in achieving other goals. The key factor is the formation of a full-fledged personality, which is a long and complex process that depends on many aspects that affect the result. Education in the modern world is not just a process of transmitting useful information, it is the development of a type of thinking that will allow for a multilateral and interdisciplinary analysis of each problem situation that a future graduate may face in his professional activity.

At the same time, within the framework of achieving the Sustainable Development Goals, one of the important problems is the infrastructure quality, which provides favorable and unfavorable conditions for the project implementation. The education quality depends on the infrastructure development in a particular area. In the Russian Federation, the subjects have characteristic problems caused by remoteness from economic centers, climatic conditions, population, etc.

In this regard, it seems necessary to conduct a conditions qualitative analysis for the transition to a new type of educational relations and the problems faced by various territories. The purpose of presented research is to analyze the existing problems in the process of implementing the concept of sustainable education and to elaborate proposals for their solution.

\section{MATERIALS AND METHODS}

The study was based on international and Russian policy documents, as well as federal and regional acts, local acts of educational institutions and teaching materials. The study also examined the scientific and methodological understanding of the provisions of the current legal acts presented in contemporary research.

The sustainable development concept, actively implemented at the moment, originates in the 70 s of the twentieth century. It should be noted that the "sustainable development" concept appears in the Russian legal field back in the 1990s (Presidential Decrees No. 236 "On State Strategy of the Russian Federation on Environmental Protection and Sustainable Development" and No. 440 "On the Concept of Transition of the Russian Federation to Sustainable Development"). The Concept of the Transition of the Russian Federation to Sustainable Development defines the term as "stable socio-economic development which does not destroy its natural basis". A key document in the current period is Decree No. 474 "On the National Development Goals of the Russian Federation for the period until 2030", which includes the definition of a goal for self-realization and development of talents through entering the Russian Federation into the top ten countries in the world for the quality of general education and creating an effective system of higher education. Despite this, Russia ranks 53rd in the World Sustainability Index.

Speaking about the need for sustainable education, it is impossible not to mention the legal support issues for distance learning in the Russian Federation education system. In 2007, Russia and the CIS member states signed an agreement " "On coordination of work in the field of informatization of the education systems of the Commonwealth of Independent States". In Russia, laws and by-laws regulating the education organization with the use of distance learning technologies are issued. In particular, the Russian Federation government Decree No. 313 "On the Russian Federation state program approval Information Society". However, neither the Federal Law "On Education in the Russian Federation" nor any regulatory legal acts contain articles that would regulate in detail the requirements for the process of obtaining education using distance technologies.

The distance learning development will enable people, including those with disabilities, to exercise their right to education, enshrined in Part 1 of Article 43 of the Russian Federation Constitution. Education should accompany a person throughout his life. Only with education so understood and so implemented can a humanistic culture be formed.

The legal block analysis of materials, based on theoretical methods (in particular, methods of deduction and induction, and also methods of generalization and content analysis), allowed us to form an idea of the current state of educational relations legal regulation problem and to understand that there is a transition to the educational policy revision of the basic trends, taking into account the targets achievement defined in the National Project "Education

Taking into account the state strategy, relevant regional projects were also formed. In particular, the Sverdlovsk region is a participant in 6 directions: "Modern school", "Success of every child", "Digital educational environment", "Young professionals", "Social activity", "Patriotic education".

Despite the fact that the projects implementation was planned until 2024, the deadline was extended until 2030 on the basis of Presidential Decree No. 474 (the reason for the extension was the pandemic). So, it turned out that some local acts adopted during this period "restrict basic human rights and do not comply with some federal laws" [2] which did not contribute to the task implementation set. 
The UNECE Strategy on Education for Sustainable Development determines not only the substantive nature of changes in education, but also the methodological transformation of the modern educational system, taking into account a multilateral and interdisciplinary approach. The national project "Education" takes into account these principles, implementing four main directions: updating the content, creating a modern infrastructure, training, retraining and professional personnel advanced training, creating effective management mechanisms.

A special place among the studied materials is occupied by statistical data that allowed us to study the processes, assessing their quantitative and qualitative parameters.

In 2014, the first Rating of Russian Sustainable Development cities was presented. According to the data for 2020, the leader of this rating is Moscow, and the top 30 includes cities such as Tyumen, Kazan, Yekaterinburg, Ufa, Perm, etc. At the same time, the Urals and Western Siberia monotown, traditionally fall into the lower part of the rating. This fact indicates the heterogeneity of the territories characteristics even within the same federal district. The Rating results analysis also demonstrates the relationship between the urban development level and the education quality aimed at the human capital development: cities with a high level of higher and secondary education occupy high positions in the Ranking and have a higher potential for sustainable development in the medium term.

In the context of the COVID-19 pandemic, in July 2020, Russia announced progress in the Sustainable Development Goals implementation at a high-level Political Forum with the United Nations support. A number of projects were presented that have a positive impact on the education system, one of which was the creating project an online platform for vocational training of persons with disabilities throughout Russia (while the percentage of students with disabilities, disabled people and disabled children has not changed for several years $0.5 \%$ ). At the same time, online platforms cannot be called a means of making the education process fully accessible, since the lack of personal computers and laptops for many people, as well as a weak Internet signal in territories located outside urban settlements, hinder the knowledge acquisition. At the same time, according to the annual Global Digital 2021 report, the number of Internet users in Russia is 124 million people, which indicates an Internet penetration rate of $85 \%$.

The study used empirical scientific methods (observations, comparison, testing), which allowed us to draw conclusions about the current Russian education problems, especially in the context of the process transformation in connection with the pandemic. Based on the identified problem areas in the sustainable education concept implementation, the need to involve auxiliary methods was identified: polling and interviewing. The study empirical basis was minisurveys in oral and written forms, as well as interviewing. The respondents were full-time students and undergraduates of Yekaterinburg universities.

The scientific research basis was the work of domestic and foreign researchers involved in the sustainable education development. The studies, taking into account the content and methodological basis, were grouped, which made it possible to form two scientific concepts blocks.

The first research block is related to the analysis of the general theoretical principles characteristics and the implementing sustainable education process. Researchers in this field analyze the legal framework, systematize the prerequisites and pay attention to existing problems in general $[3,4,5]$. These studies allowed us to get an idea of the general problems that arise in the process of forming prerequisites for sustainable development.

The second research block is a particular problems analysis in specific areas of educational activity, which allows scientists to conduct a more targeted analysis and offer solutions to problems within a separate activities range $[6,7,8]$. These studies contain a fairly serious and in-depth individual problems analysis by education levels and work methods, which allowed us to draw qualitative conclusions about possible ways to solve existing problems.

Thus, the theoretical and practical methods combination allowed us to draw a number of conclusions about the practical implementation problems of the sustainable education concept in the context of the territorial development specifics. Using the forecasting method, we have formulated the main groups of risks that should be avoided during the educational relations transformation.

\section{RESULTS AND DISCUSSION}

Based on the conducted research, conclusions were drawn about the problems that educational institutions and participants in educational relations face in practice, and their possible solutions were proposed.

The development and spread of the Internet has reformed the educational system, and distance education, according to a number of experts, has certain advantages, such as the ability to study at any time and in any place, mobility, individual approach, diversity and a large amount of available information resources. At the same time, it should be noted that according to the microcensus data, there are only 304 people with higher education per 1000 people in Russia [9]. This indicator is lower than in the UK, USA, Canada, Japan and a number of other countries. Consequently, increasing the level of 
access to education makes it possible to increase the number of educated people.

To implement the transition to distance learning in the Russian Federation, various regional and local acts regulating this issue have been adopted. However, the distance learning possibilities realization as part of the strategy implementation to involve more people in the learning process is complicated by a number of problems.

The first problem is the lack of technical equipment. The study results by the Public Chamber were published, according to which a third of school students noted that they did not have a personal computer necessary for distance learning. In the spring of last year, the Russian Federation Ministry of Education gave permission for the early school year completion to students of junior and middle grades, because it was impossible to ensure the full educational programs implementation using distance learning technologies. This led to the educational process disruption, part of the educational program was postponed to the next year. Based on the infrastructure provision schools analysis conducted by the Russian Federation Ministry of Education with the assistance of the Ministry of Digital Development, it was revealed that no more than $25 \%$ of students have the necessary means to switch to distance learning. Speaking about this problem, we note that there is a second side - the lack of technical teachers capabilities. As of 2019, the Russian Federation Federal State Statistics Service revealed that only $69.4 \%$ of families have a computer. Despite the official statistics, many respondents interviewed by us during the interview drew attention to communication interruptions affecting the remote work quality.

The second distance learning problem is its quality. At the end of December 2020, the Russian analytical newspaper RBC published the words of the Russian Federation Minister of Science and Higher Education V. N. Falkov that the distance education quality differs from the full-time education quality for the worse. We conducted a survey on the possibility of obtaining highquality education in a distance format. 50 people took part in the survey: students aged 18 to 25 years of fulltime bachelor's and master's degrees in various fields. $52 \%$ of respondents gave a negative answer to this question. In their opinion, education received in a distance format cannot be of high quality.

Russian public figure V. V. Grib, in an interview with the Russian Newspaper representatives, said that the main distance education problem as of December 2020, compared with spring, when there were acute unpreparedness teachers problems and technical failures, is the lack of students motivation.

Our surveys have confirmed the colleagues conclusions that students choose the least responding innovative style to the changes that have arisen [10]. We can note that the need to study remotely with the technical means involvement caused negative emotions in the majority of respondents, which is associated not only with the inability to work with new resources, but also with the unwillingness to master them. As a result of more in-depth interviews, we also found that students rarely put the educational content quality in the foreground, giving priority to the time they spend on familiarization with the topic.

One of the ways to solve the students' lack of motivation problem may be to take into account the students opinion about the classes organization, transfer part of the educational content to a convenient and familiar field for students. At the same time, the education availability itself in digital format is currently quite a difficult problem to solve, taking into account the territories specifics: access to all resources cannot be fully provided in rural areas. Also, some of the resources are not supported in foreign countries, which makes it difficult to attract students from other countries. The reducing universities policy (in less than 20 years, the number of universities has decreased by more than 1,000) has led to the fact that in some regions of Russia, most of the educational programs are implemented by 2-3 universities, which sharply reduces competition and may lead to a decrease in the education level in the future.

For the first time, the term "continuing education" was introduced in 1968 in the UNESCO General Conference materials. Since the end of the 20th century, the continuing education idea has found supporters in many countries and has become the main educational reforms principle. The need for new approaches to the educational process has led to the active innovative educational programs development of additional education. At the same time, the number of educational programs for adults is not growing so fast, many educational institutions are not ready to work with a new contingent. In the course of a survey conducted among USUE students about whether students intend to enroll in a master's degree or receive a second higher education, $54 \%$ of respondents answered negatively. Also, in the study course, students were asked to answer the question of whether they plan to work in their specialty, take advanced training courses and whether they consider education affordable. According to this study results, $44 \%$ of respondents do not plan to work in the specialty in which they are currently studying. $46 \%$ of future graduates do not plan to take advanced training courses and only $50 \%$ of respondents consider education affordable.

We agree with the opinion that education "for sustainable development involves solving a number of tasks related to the education formation as the main social institution, as well as the new values system development"[11]. It is necessary to build educational clusters so that students understand the education value as a process, not the end result. 


\section{CONCLUSION}

As a result of the conducted research, possible risks of educational strategies in modern Russia were identified, taking into account the specifics of the individual territorial units problems.

The educational centers formation in large megacities accumulating advanced trends in the education system leads to two types of consequences. Firstly, competition in such centers is increasing, which leads to a reduction in universities - only large ones remain that are able to support the subject development by providing the regional labor market with specialists. Thus, 10 cities in Russia have federal universities (Kaliningrad, Vladivostok, Kazan, Simferopol, Arkhangelsk, Yakutsk, Stavropol, Krasnoyarsk, Rostov-on-Don, Yekaterinburg), and 33 cities are supporting ones. The problem is connected with the fact that, contrary to expectations, these universities could not reach the first positions in the rankings of universities, where the Moscow and St. Petersburg universities continue to prevail. Secondly, regional centers that are located on the periphery, especially narrow-profile ones, lose their advantages and the education quality in them begins to decline. In some subjects, programs are implemented on the basis of branches and representative large universities offices, which, unfortunately, do not always take into account the labor market specifics in a particular region. The Far North environmental problems are not identical to the Russia center problems. This leads to the fact that graduates cannot find a job in their region in their specialty and are forced to migrate or choose a less qualified job not in their specialty. Thus, the university enlargement trend does not always have a positive effect, which must be taken into account and form educational transformations taking into account the demand of the regions.

Despite the fact that many researchers actively call for accelerated digitalization and the transition to online mode on a permanent basis of a number of organizations in order to implement the sustainable development principles [12], technical equipment is the second risk in the framework of innovative educational policy. Not every territory has the necessary capabilities to implement, for example, high-quality distance education. The transition to remote communication between a teacher and a student requires serious preparation on the part of all participants in educational relations. If these changes are forced, as happened during the pandemic in 2019, the education quality may fall. Part of the Russian Federation territories, especially the northern ones, still faces problems of lack of access to the Internet at the proper level. This leads to the following group of risks distrust of innovation: participants in educational relations, having received negative experience, are biased towards any type of remote interaction in the learning process. This problems group can be solved only by complex methods: improving the technical equipment and information policy of educational institutions openness.

The group of risks associated with adherence to the traditional way of education is largely due to the low students motivation who still do not consider education as an element of professional activity. This problem can be solved only in one way - active educational organizations cooperation with employers focused on the territories sustainable development principles implementation

Thus, sustainable education seems to be a trend due to the challenges of the time, but the transition itself cannot be abrupt - it is a process that requires preparation and individual innovations gradual introduction that contribute not only to new educational activity forms, but also to its new content.

\section{REFERENCES}

[1] S.A. Stepanov, Education for sustainable development through the prism of the Bologna process in European education. Bulletin of environmental education in Russia 2 (2008) pp. 6-7.

[2] G.B. Romanovsky, 2019-NCOV as a hybrid threat to the human rights system. Constitutional and municipal law 7 (2020) pp. 34-38.

[3] Zh.O. Nebessayeva, G.B. Kunzhigitova, K.M. Bekbolatova, Current tasks of education development for sustainable development of pedagogical sciences. Science and education: new time 1(42) (2021) pp. 26-36.

[4] V.V. Zinchenko, Global institutional transformations and the prospects of sustainable development of society in the context of the internationalization of higher education. Perspectives of Science and Education 2(44) (2020) pp. 10-18.

[5] N.D. Bardakov, Digital transformation of education and / or education for sustainable development. Innovative scientific research 4-3(6) (2021) pp. $167-$ 172.

[6] O.A., Granichina, S.A. Kotova, Ideas of education for sustainable development as basic guidelines for ensuring the quality of school education. Psychology of education in a multicultural space 4(16) (2011) pp. 5-9.

[7] O. Kazakova, Education for sustainable development in english language classes. Language. Culture. Education 6 (2021) pp. 57-61.

[8] L.Yu. Ivanova, Environmental education and education for sustainable development in the 
Russian school: present and future. Bulletin of the Institute of Sociology 8, 4(23) (2017) pp. 90-112.

[9] Education in Figures: 2021: A Brief Statistical Compilation. NRU HSE, 2021, p. 132.

[10] N.A. Buravleva, S.A. Bogomaz, Personal characteristics of students as prognostic characteristics of their readiness for innovative activity. Siberian psychological journal 76 (2020) pp. 155 - 180. DOI: https://doi.org/10.17223/17267 080/76/10.

[11] T.S. Korotkova, D.I. Zakirova, Environmental education and education for sustainable development: general and special. Bulletin of Turan University 1(89) (2021) pp. 110-115.

[12] T. A. Lanshina, V. A. Barinova, A. D. Kondratyev, M. V. Romantsov, Sustainable development and digitalization: the unusual crisis of COVID-19 requires original solutions. Bulletin of international organizations: education, science, new economy. 15(4) (2020) pp. 91-114. DOI: https://doi.org/10.17323/1996-7845-2020-0405 . 